\title{
Splenic Hilum
}

National Cancer Institute

\section{Source}

National Cancer Institute. Splenic Hilum. NCI Thesaurus. Code C33601.

The area of the spleen through which the vessels and nerves enter or exit the org an. 